\title{
Avaliação dos Microrganismos Viáveis Potencialmente Patogênicos em Bioaerossóis em uma Unidade de Terapia Intensiva
}

\author{
Tharinne Oliveira Silva Cavalheiro, ${ }^{1}$ Dora Inés Kozusny-Andreani ${ }^{2}$
}

\section{RESUMO}

Bioaerossóis são partículas transportadas pelo ar que se originam de microrganismos vivos, como bactérias, fungos e vírus e podem permanecer suspensos e viáveis na corrente de ar por longos períodos de tempo. Seus componentes têm efeitos negativos, especialmente na saúde de pessoas imunocomprometidas. Objetivou-se avaliar a presença de microrganismos viáveis potencialmente patogênicos em bioaerossóis de uma Unidade de Terapia Intensiva de um hospital do noroeste paulista. Para a pesquisa foram colhidas amostras do ar de locais definidos. Todas as amostras foram cultivadas em Placas de Petri contendo meios seletivos e não seletivos para bactérias e fungos, incubadas à temperatura de 370 C por 24-48h para cultivos bacterianos e de 4 a 15 dias para cultivos fúngicos. Posteriormente foi realizada a avaliação das características das colônias, bem como a identificação por métodos bioquímicos convencionais. Os resultados obtidos evidenciaram a presença de leveduras das espécies Candida albicans e Candida spp e bactérias Gram-positivas Staphylococcus aureus, S. epidermidis e Micrococcus spp, Gram-negativas Escherichia coli e Klebsiella spp. Verificou-se padrão de resistência a antibióticos em E. coli e Micrococcus spp. Já S. aureus foi sensível à maioria dos antibióticos, enquanto foi possível observar 100\% de sensibilidades para S. epidermidis e Klebsiella spp.

Palavras-chave: aerossóis; bactéria gram-negativa; bactéria gram-positiva; leveduras.

\section{EVALUATION OF POTENTIALLY PATHOGENIC VIABLE MICROORGANISMS} IN BIOAEROSOLS OF AN INTENSIVE CARE UNIT

\section{ABSTRACT}

Bioaerosols are airborne particles that originate from living microorganisms such as bacteria, fungi and viruses and can remain suspended and viable in the air stream for long periods of time. Its components have negative effects, especially on the health of immunocompromised people. In order to characterize bioaerosols as to their viable microbial composition in the ITU of a hospital in the northwest of São Paulo, this research was conducted with a qualitative and quantitative approach, applied nature and experimental procedure. For the research, air samples were taken from defined locations. All samples were cultivated in Petri dishes containing selective and non-selective media for bacteria and fungi, incubated at $37{ }^{\circ} \mathrm{C}$ for $24-48 \mathrm{~h}$ for bacterial cultures and 4 to 15 days for fungal cultures. Subsequently, the characteristics of the colonies were evaluated as well as the identification by conventional biochemical methods. The results showed the presence of Candida albicans and Candida spp. Yeasts and Gram-positive bacteria Staphylococcus aureus, S. epidermidis and Micrococcus spp. Gram-negative Escherichia coli and Klebsiella spp. High antibiotic resistance was found in E. coli and Micrococcus spp. S. aureus was sensitive to most antibiotics, whereas S. epidermidis and Klebsiella spp showed $100 \%$ sensitivity.

Keywords: aerossol; gram-negative bacteria; gram-positive bacteria; yeast.

RECEBIDO EM: 30/10/2019

MODIFICAÇÕES SOLICITADAS EM: 25/11/2020

ACEITO EM: 21/3/2021

\footnotetext{
${ }^{1}$ Universidade Brasil. Fernandópolis/SP, Brasil.

${ }^{2}$ Autora correspondente. Universidade Brasil. Estrada Projetada F1 - Fazenda Santa Rita. Fernandópolis/SP, Brasil. CEP 15600-000. http://lattes.cnpq.br/1260217332585007. https://orcid.org/0000-0003-3579-6419. doraines@terra.com.br
} 


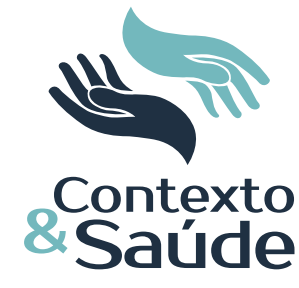

\section{INTRODUÇÃO}

A qualidade biológica do ar varia entre diferentes ambientes. O âmbito de assistência à saúde enfrenta ameaças diretas e inevitáveis dos bioaerosóis infecciosos (NASIR et al., 2015). Os poluentes biológicos ou os bioaerossóis representam ameaças iguais ou mais graves que os contaminantes químicos. Bioaerossóis são partículas transportadas pelo ar que se originam de microrganismos vivos, como bactérias, fungos, vírus e parasitas, podendo ser nocivos à saúde humana, pois apresentam capacidade de permanecer suspensos no ar por longos períodos, e o tempo entre a exposição e os danos à saúde geralmente é muito curto (MIRHOSEINI et al., 2015; SIVAGNANASUNDARA et al., 2019).

Os agentes microbianos contidos nos bioaerossóis podem contribuir para a transmissão e aquisação de doenças infecciosas. Alguns agentes infecciosos, isto é, microganismos capazes de iniciar infecções ou doenças infecciosas, são constituintes normais da microbiota humana e animal, no entanto eles podem iniciar uma doença quando ocorrem alterações no agente, no hospedeiro ou em ambos. Mais comumente, os agentes residem fora do hospedeiro e devem ser transmitidos de fontes externas para o ser humano ou animal, iniciando uma infecção (GODINI et al., 2015).

O risco de infecções transmitidas pelo ar, especialmente em hospitais e outros estabelecimentos de saúde, pode ser alto, pois pode haver espaços confinados nos quais os bioaerossóis podem atingir níveis infecciosos. O acúmulo destas partículas infecciosas agrava os desafios da saúde nos países em desenvolvimento, à medida que o papel dos bioaerossóis nas Infecções Relacionadas à Assistência à Saúde (Iras) é comprovado pelas evidências crescentes sobre a propagação de doenças por via aérea (GODINI et al., 2015, RIBEIRO et al., 2019; TOLABI; ALIMOHAMMADI; HASSANVAND, 2019).

A exposição de pacientes, profissionais de saúde e visitantes a esses microrganismos é inevitável. O estado imunológico de pessoas e a inoculação de patógeno virulento determinam o desenvolvimento de doenças (GHANIZADEH; GODINI, 2018).

A presença de bioaerossóis em hospitais, especialmente em diferentes enfermarias, pode ser atribuída a pacientes infectados que transmitem esses contaminantes por via aérea. A transmissão ocorre quando patógenos microbianos são liberados de um paciente infectado para indivíduos vulneráveis por meio de atividades como tossir, espirrar e falar. Outras fontes possíveis de bioaerossóis no hospital podem ser roupas ou outros itens pessoais pertencentes aos pacientes (SETLHARE et al., 2014).

As Iras são uma das principais causas de morbimortalidade em Unidades de Terapia Intensiva (UTIs) e Unidades de Terapia Intensiva Neonatal (Utins). Organismos que causam essas infecções estão frequentemente presentes nas superfícies ao redor do paciente, em dispositivos encontrados nos hospitais e nos bioaerossóis (CALFEE, 2011 ; WALTER; HALLER; QUINTEN 2018; RIBEIRO et al., 2019). Essas infecções são mais frequentes em UTIs, onde surtos geralmente se originam, aumentam a morbimortalidade, a resistência a antimicrobianos, prolongam a duração das internações hospitalares e, consequentemente, os custos

Editora Unijuí - Revista Contexto \& Saúde - ISSN 2176-7114 - v. 21, n. 43, jul./set. 2021 
com a saúde (MAGILL et al., 2014; LAX; GILBERT, 2015; AGABA et al., 2017; TEERAWATTANAPONG; PANICH; KULPOKIN, 2018). O desenvolvimento e a frequência das Iras são influenciados por vários fatores que podem ser categorizados em três principais: agentes microbianos, suscetibilidade do paciente e fatores ambientais (SIVAGNANASUNDARA et al., 2019).

A incidência das Iras é um problema sério e generalizado, com a estimativa de 1 em 10 pacientes adquirindo uma infecção durante uma internação hospitalar. Existe uma gama de microrganismos potencialmente patogênicos associados a infecções hospitalares, muitos dos quais são patógenos oportunistas que frequentemente causam infecções respiratórias, particularmente em pacientes imunocomprometidos. Para determinar a extensão do problema, faz-se necessário realizar amostragens para verificar e quantificar a presença de bioaerossóis, dado que a microbiota pode variar entre diferentes UTIs e as assinaturas microbianas relacionadas às doenças infecciosas transmitidas pelo ar nessas unidades permanecerem pouco exploradas (BIELAWSKA-DRÓZD et al., 2018; RIBEIRO et al., 2019). Nesse contexto objetivou-se na presente pesquisa avaliar a presença de microrganismos viáveis potencialmente patogênicos em bioaerossóis de uma Unidade de Terapia Intensiva de um hospital do noroeste paulista.

\section{MATERIAL E MÉTODOS}

\section{Tipo de pesquisa}

Trata-se de uma pesquisa de natureza aplicada, no sentido de gerar conhecimento da qualidade do ar ao determinar seu nível de contaminação dentro de uma Unidade de Terapia Intensiva (UTI) adulta com a captação de bioaerossóis em Placa de Petri, levando também a identificar os microrganismos presentes nos bioaerossóis e suas respectivas resistências antimicrobianas.

Em consonância com Silveira e Córdova (2009), trata-se de um estudo quantitativo analítico, o qual busca informações para fornecer explicações e, ao mesmo tempo, quantificar os microrganismos pesquisados, centrando-se na objetividade.

\section{Local de estudo - Caracterização}

A pesquisa foi realizada em uma UTI adulta de dez leitos, um deles de isolamento, em um hospital de médio porte do noroeste paulista nos meses de março, maio e junho de 2019. Trata-se de um setor crítico, de acesso restrito e provido de recursos humanos e materiais necessários no tratamento de pacientes graves, os quais serão assistidos continuamente por uma equipe interdisciplinar promovendo o tratamento adequado para sua condição clínica (MURAKAMI; SANTOS, 2015).

Por suas características singulares, o ambiente conta com uma estrutura física diferenciada de outros setores hospitalares, segundo a RDC no 50 (BRASIL, 2002), tais como vestiário de colaboradores, copa, banheiro de pacientes, entre outros, conforme planta física do local da pesquisa (Figura 1).

Editora Unijuí - Revista Contexto \& Saúde - ISSN 2176-7114 - v. 21, n. 43, jul./set. 2021 
O local estabelecido para a pesquisa envolve três aspectos a serem discutidos neste estudo: a climatização artificial, a vulnerabilidade do público atendido e equipe. Visando a captar os bioaerossóis de maneira transversal dentro do ambiente, as Placas de Petri foram dispostas sobre a geladeira destinada ao armazenamento de dietas de pacientes (1), sobre o balcão de prescrição (2) e na entrada dos banheiros de colaboradores (3), como pode ser visto na Figura 1.

Figura 1 - Layout da planta física da Unidade de Terapia Intensiva do hospital em estudo

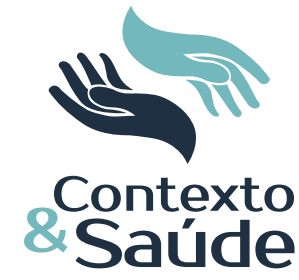

1 Local de coleta 1 , sobre a geladeira destinada à dieta de paciente

2 Local de coleta 2, sobre o balcão de prescrição

3 Local de coleta 3, na entrada dos banheiros de colaboradores. Fonte: As autoras (adaptado do original).

\section{Sujeito do estudo}

A dispersão de microrganismos no ar, em especial em locais climatizados, pode determinar um problema sério aos pacientes (e profissionais) em uma UTI e requer a necessidade de se realizar a amostragem para verificar e quantificar a presença de bioaerossóis no ar desse ambiente (FLETCHER et al., 2004). Ao relacionar este fato ao perfil de pacientes atendidos dentro de uma UTI, os componentes dos bioaerossóis ganham destaque e importância.

\section{Coleta de dados}

As amostras do ar referente ao ambiente estudado foram coletadas utilizando-se a técnica de sedimentação passiva, de acordo com a metodologia descrita por Kalwasińska, Burkowska e Wilk (2012) e Hayleeyesus e Manaye (2014): utilizaram-se um dueto de Placas de Petri com meios seletivos distintos, sendo eles: Tryptone soya Agar e (TSA, OXOID $)$ para cultivo de bactérias, e para fungos

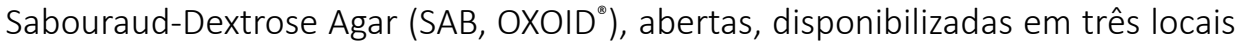
diferentes dentro da UTI, por 12 horas, e na sequência outro dueto de placas por mais 12 horas, fechando um ciclo de 24 horas de coleta. As placas foram identificadas por data, horário, meio de cultura e local de coleta. Em seguida, foram acondicionadas em caixa isotérmica e transportadas ao laboratório de microbiologia da Universidade Brasil, Campus Fernandópolis-SP, todas incubadas à temperatura de $37 \stackrel{\circ}{-}$, por $24-48 \mathrm{~h}$, as placas contendo meio TSA, e as de meio SAB por 4 a 15 dias.

Editora Unijuí - Revista Contexto \& Saúde - ISSN 2176-7114 - v. 21, n. 43, jul./set. 2021 
Após esse período foi realizada a contagem utilizando contador manual e a avaliação das características das colônias em relação à forma, tamanho e cor. A metodologia de coloração de Gram foi empregada para identificar as bactérias Gram-positivas e Gram-negativas que cresceram no meio.

Para a caracterização das espécies de enterobactérias e outros bacilos Gram-negativos não fastidiosos foi utilizado o sistema padronizado para identificação Api 20E e para a caracterização das espécies bacterianas Gram-positivas foram realizados os testes de: catalase, coagulase, DNAse, oxidase e hemólise (WINN-JUNIOR; ALLEN; JANDA, 2012).

Para a identificação dos fungos foram analisadas as características macro e microscópicas, assim como métodos bioquímicos convencionais (WINN-JUNIOR; ALLEN; JANDA, 2012). As leveduras isoladas foram diferenciadas em meio Chromoagar-Candida (Difco $\left.{ }^{\circ}\right)$

\section{Perfil de suscetibilidade bacteriana aos antimicrobianos}

Os isolados bacterianos foram avaliados quanto ao perfil de suscetibilidade aos antimicrobianos. Para tal fim, empregou-se o método de Kirby Bauer (difusão em placas). Os resultados foram interpretados de acordo com os parâmetros estabelecidos pelo Clinical \& Laboratory Standards Institute (CLSI 2015, 2019).

\section{Análise dos dados}

Os dados obtidos foram compilados em um banco de dados em formato Microsoft Excel ${ }^{\circ}$, sendo alimentado com os resultados de identificação dos microrganismos e contagem das Unidades Formadoras de Colônias (UFCs).

Além disso foi realizada análise percentual e estatística descritiva da ocorrência de microrganismos por local avaliado e por coleta realizada. Os resultados percentuais das quatro coletas efetuadas foram computados em termos de estatísticas descritivas (média, desvio padrão e mediana) com o objetivo de observar possíveis diferenças significativas na ocorrência de cada um dos microrganismos identificados quando os locais foram comparados entre si. A relevância dessa abordagem foi observar se a ocorrência dos diferentes microrganismos diferiu significativamente em relação aos locais estudados e, em caso afirmativo, em qual local foi possível observar a maior e menor ocorrência.

Foi aplicado teste não paramétrico Kruskal-Wallis e um teste de proporção para verificar a presença de diferenças significativas na comparação dos percentuais de resistência e sensibilidade dos microrganismos no antibiograma.

Realizou-se, ainda, a Análise de Componentes Principais (ACP) (abordagem multivariada) com o objetivo de verificar relações entre os locais de coleta e os tipos de microrganismos, adotando um nível de significância de $p<0,05$ ou 5\%. A ACP reduz o número de variáveis agrupando-as em um gráfico bidimensional, relacionando dois gráficos por quadrante. Esta abordagem permite encontrar um meio matemático de condensar a informação contida em diversas variáveis originais em um conjunto menor de variáveis estatísticas, chamadas de componentes, com uma perda mínima de informação, ou seja, que estes componentes

Editora Unijuí - Revista Contexto \& Saúde - ISSN 2176-7114 - v. 21, n. 43, jul./set. 2021 
consigam explicar quase que a totalidade da variação dos dados (geralmente acima de $60 \%$ já se considera aceitável, segundo Zar (2009). Para isso utilizou-se o Software Minitab 18 (Minitab Inc.) e Statistica 12 (StatSoft ${ }^{\circ}$ Inc.).

\section{RESULTADOS}

\section{Ocorrência de microrganismos}

A Tabela 1 mostra o percentual da ocorrência dos microrganismos identificados nas áreas analisadas no estudo: setores banheiros, geladeira e balcão.

Tabela 1 - Percentual de ocorrência dos microrganismos identificados nas diversas áreas de coleta da UTI

\begin{tabular}{|c|c|c|c|c|c|c|}
\hline \multirow{3}{*}{ Microrganismos } & \multicolumn{6}{|c|}{ Coleta 1} \\
\hline & \multicolumn{2}{|c|}{ Banheiros } & \multicolumn{2}{|c|}{ Geladeira } & \multicolumn{2}{|c|}{ Balcão } \\
\hline & $\mathrm{N}$ & $\%$ & $\mathrm{~N}$ & $\%$ & $\mathrm{~N}$ & $\%$ \\
\hline Candida albicans & 3 & 17,65 & 3 & 27,27 & 7 & 38,89 \\
\hline Candida spp & 0 & 0,00 & 0 & 0,00 & 0 & 0,00 \\
\hline Escherichia coli & 3 & 17,65 & 1 & 9,09 & 1 & 5,56 \\
\hline Klebsiella spp & 0 & 0,00 & 0 & 0,00 & 1 & 5,56 \\
\hline Micrococcus spp & 5 & 29,41 & 4 & 36,36 & 5 & 27,78 \\
\hline Staphylococcus aureus & 3 & 17,65 & 1 & 9,09 & 2 & 11,11 \\
\hline Staphylococcus epidermidis & 3 & 17,65 & 0 & 0,00 & 1 & 5,56 \\
\hline \multirow[t]{2}{*}{ Negativo (sem crescimento) } & 0 & 0,00 & 2 & 18,18 & 1 & 5,56 \\
\hline & \multicolumn{6}{|c|}{ Coleta 2} \\
\hline \multirow[t]{2}{*}{ Microrganismos } & \multicolumn{2}{|c|}{ Banheiros } & \multicolumn{2}{|c|}{ Geladeira } & \multicolumn{2}{|c|}{ Balcão } \\
\hline & $\mathrm{N}$ & $\%$ & $\mathrm{~N}$ & $\%$ & $\mathrm{~N}$ & $\%$ \\
\hline Candida albicans & 4 & 44,44 & 3 & 42,86 & 6 & 60,00 \\
\hline Candida spp & 0 & 0,00 & 0 & 0,00 & 0 & 0,00 \\
\hline Escherichia coli & 1 & 11,11 & 0 & 0,00 & 1 & 10,00 \\
\hline Klebsiella spp & 0 & 0,00 & 0 & 0,00 & 0 & 0,00 \\
\hline Micrococcus spp & 1 & 11,11 & 2 & 28,57 & 2 & 20,00 \\
\hline Staphylococcus aureus & 3 & 33,33 & 1 & 14,29 & 1 & 10,00 \\
\hline Staphylococcus epidermidis & 0 & 0,00 & 1 & 14,29 & 0 & 0,00 \\
\hline \multirow{2}{*}{ Negativo (sem crescimento) } & 0 & 0,00 & 0 & 0,00 & 0 & 0,00 \\
\hline & \multicolumn{6}{|c|}{ Coleta 3} \\
\hline \multirow[t]{2}{*}{ Microrganismos } & \multicolumn{2}{|c|}{ Banheiros } & \multicolumn{2}{|c|}{ Geladeira } & \multicolumn{2}{|c|}{ Balcão } \\
\hline & $\mathrm{N}$ & $\%$ & $\mathrm{~N}$ & $\%$ & $\mathrm{~N}$ & $\%$ \\
\hline Candida albicans & 6 & 50,00 & 3 & 50,00 & 8 & 50,00 \\
\hline Candida spp & 1 & 8,33 & 0 & 0,00 & 0 & 0,00 \\
\hline Escherichia coli & 3 & 25,00 & 2 & 33,33 & 1 & 6,25 \\
\hline Klebsiella spp & 0 & 0,00 & 0 & 0,00 & 0 & 0,00 \\
\hline Micrococcus spp & 1 & 8,33 & 0 & 0,00 & 6 & 37,50 \\
\hline Staphylococcus aureus & 1 & 8,33 & 1 & 16,67 & 0 & 0,00 \\
\hline Staphylococcus epidermidis & 0 & 0,00 & 0 & 0,00 & 0 & 0,00 \\
\hline Negativo (sem crescimento) & 0 & 0,00 & 0 & 0,00 & 1 & 6,25 \\
\hline
\end{tabular}




\begin{tabular}{lcccccc}
\hline \multirow{2}{*}{ Microrganismos } & \multicolumn{9}{c}{ Coleta 4 } \\
\cline { 2 - 7 } & \multicolumn{2}{c}{ Banheiros } & \multicolumn{2}{c}{ Geladeira } & \multicolumn{2}{c}{ Balcão } \\
\cline { 2 - 7 } & $\mathrm{N}$ & $\%$ & $\mathrm{~N}$ & $\%$ & $\mathrm{~N}$ & $\%$ \\
\hline Candida albicans & 13 & 59,09 & 14 & 53,85 & 8 & 40,00 \\
Candida spp & 0 & 0,00 & 1 & 3,85 & 0 & 0,00 \\
Escherichia coli & 3 & 13,64 & 2 & 7,69 & 5 & 25,00 \\
Klebsiella spp & 0 & 0,00 & 0 & 0,00 & 0 & 0,00 \\
Micrococcus spp & 4 & 18,18 & 6 & 23,08 & 3 & 15,00 \\
Staphylococcus aureus & 1 & 4,55 & 1 & 3,85 & 1 & 5,00 \\
Staphylococcus epidermidis & 1 & 4,55 & 0 & 0,00 & 2 & 10,00 \\
Negativo (sem crescimento) & 0 & 0,00 & 2 & 7,69 & 1 & 5,00 \\
\hline
\end{tabular}

$\mathrm{N}$ : número de ocorrência dos referidos microrganismos em cada local avaliado.

$$
\text { Fonte: As autoras. }
$$

Os resultados da Tabela 1 indicam que o microrganismo Candida albicans apresentou maior ocorrência em relação aos demais em todos os locais avaliados e coletas realizadas. Quanto aos banheiros, os microrganismos que se destacaram em termos de ocorrência foram: Candida albicans, Escherichia coli, Micrococcus spp e Staphylococcus aureus. A geladeira apresentou maiores ocorrências de Candida albicans e Micrococcus spp e o balcão apresentou maiores ocorrências de Candida albicans, Escherichia coli e Micrococcus spp.

A Tabela 2 evidencia as estatísticas descritivas da ocorrência dos diferentes microrganismos em relação aos locais avaliados no estudo.

Tabela 2 - Estatísticas descritivas da ocorrência dos diferentes microrganismos nos locais avaliados no estudo

\begin{tabular}{|c|c|c|c|c|c|c|c|}
\hline \multirow{3}{*}{ Microrganismos } & \multicolumn{6}{|c|}{ Locais de coleta } & \multirow{3}{*}{ Valor $\mathrm{p}^{1}$} \\
\hline & \multicolumn{2}{|c|}{ Banheiros } & \multicolumn{2}{|c|}{ Geladeira } & \multicolumn{2}{|c|}{ Balcão } & \\
\hline & Média $\pm D P^{2}$ & $\mathrm{Md}^{3}$ & Média $\pm D P$ & $\mathrm{Md}$ & Média $\pm D P$ & $\mathrm{Md}$ & \\
\hline Candida albicans & $42,8 \pm 17,8$ & 47,2 & $43,5 \pm 11,7$ & 27,27 & $47,2 \pm 9,8$ & 45,0 & 0,981 \\
\hline Candida spp & $2,0 \pm 4,1$ & 0,0 & $0,9 \pm 1,9$ & 0,0 & 0,0 & 0,0 & 0,573 \\
\hline Escherichia coli & $16,8 \pm 6,0$ & 15,6 & $12,5 \pm 14,4$ & 8,4 & $11,7 \pm 9,0$ & 8,1 & 0,351 \\
\hline Klebsiella spp & $0,0 \pm 0,0$ & 0,0 & $0,0 \pm 0,0$ & 0,0 & $1,4 \pm 2,7$ & 0,0 & 0,368 \\
\hline Micrococcus spp & $16,7 \pm 9,4$ & 14,6 & $22,0 \pm 15,6$ & 25,8 & $25,0 \pm 9,8$ & 23,9 & 0,584 \\
\hline S. aureus & $15,9 \pm 12,8$ & 12,9 & $10,9 \pm 5,7$ & 11,7 & $6,5 \pm 5,1$ & 7,5 & 0,551 \\
\hline S. epidermidis & $5,5 \pm 8,3$ & 2,2 & $3,5 \pm 7,1$ & 0,0 & $3,9 \pm 4,8$ & 2,7 & 0,846 \\
\hline Negativo & $0,0 \pm 0,0$ & 0,0 & $6,4 \pm 8,6$ & 3,8 & $4,2 \pm 2,8$ & 5,2 & 0,166 \\
\hline
\end{tabular}

${ }^{1}$ Valor $\mathrm{p}$ referente ao teste de Kruskal-Wallis a $\mathrm{p}<0,05 .{ }^{2}$ Média \pm desvio padrão. ${ }^{3}$ Mediana Fonte: As autoras.

Os resultados da Tabela 2 indicam a ausência de diferenças significativas quando os percentuais de ocorrência dos microrganismos avaliados foram comparados em relação aos locais, uma vez que todos os valores $p$ foram superiores ao nível de significância do teste. Nesse contexto não houve diferenças significativas no que se refere à contaminação microbiana quando os diferentes locais foram comparados, ou seja, a natureza distinta dos locais não influenciou de forma significativa na maior ou menor ocorrência dos microrganismos. 


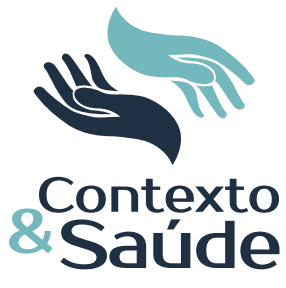

Partindo do pressuposto de que não houve resultados significativos na abordagem univariada pela aplicação do teste de Kruskal-Wallis, a abordagem multivariada faz-se necessária a fim de explorar os dados de uma forma pontual e concisa. A Análise de Componentes Principais (ACP) tem por objetivo analisar inter-relações entre as inúmeras variáveis coletadas. No caso do presente estudo, relacionar a ocorrência dos diversos microrganismos com os locais avaliados com a finalidade de obter pressuposições acerca de quais locais tendem a apresentar maior ou menor ocorrência de determinados microrganismos ou grupo de microrganismos.

A ACP resultou na extração de duas componentes principais, quando cada componente principal é uma combinação linear de todas as variáveis originais, independentes entre si e estimadas com o propósito de reter, em ordem de estimação, o máximo de informação, em termos de similaridade, com o objetivo de explicar o máximo da variação total nas primeiras componentes. A componente principal 1 (PC1) explicou 82,39\% da variação total dos dados e a componente principal 2 (PC2) explicou 17,61\% da variação total dos dados. A PC1 diferenciou de forma mais efetiva os microrganismos avaliados (Figura 2), mostrando localização na parte positiva desta componente principal os seguintes microrganismos: Candida albicans, Klebsiella spp, Micrococcus spp; e na parte negativa os seguintes microrganismos: Staphylococcus aureus, Candida, Escherichia coli e Staphylococcus epidermidis. Os resultados negativos para microrganismos localizaram-se na parte positiva da PC1. De uma forma geral, nenhuma das variáveis contribuiu para a PC2, exceto a variável negativa que se apresentou na parte negativa da PC2, entretanto a carga fatorial desta variável foi superior e significativa para a PC1.

Analisando os resultados da ACP de forma exploratória (Figura 3) é possível observar que o balcão apresentou maior ocorrência de Candida albicans e Klebsiella spp, uma vez que estes microrganismos localizaram-se no mesmo quadrante que o local mencionado. O banheiro apresentou maior ocorrência de Escherichia coli e Staphylococcus epidermidis, dado que estes microrganismos localizaram-se no mesmo quadrante que o local mencionado. A geladeira destacou-se por apresentar incidência negativa de microrganismos. Adicionalmente, Micrococcus spp apresentou ocorrência significativa em balcão e geladeira, posto que se localizou próximo a estes locais.

De uma maneira geral, Staphylococcus epidermidis e Escherichia coli apresentaram ocorrência significativa para os banheiros, ao passo que Staphylococcus aureus e Candida spp apresentaram ocorrência discreta para este local de análise. Candida albicans e Klebsiella spp mostraram ocorrência significativa para o balcão, ao passo que Micrococcus spp apresentou ocorrência discreta para este local de análise. A geladeira revelou ocorrência negativa de microrganismos de forma significativa, entretanto apresentou também ocorrência discreta de Micrococcus spp.

Editora Unijuí - Revista Contexto \& Saúde - ISSN 2176-7114 - v. 21, n. 43, jul./set. 2021 
Figura 2 - Análise de Componentes Principais evidenciando a relação entre os microrganismos identificados (A)
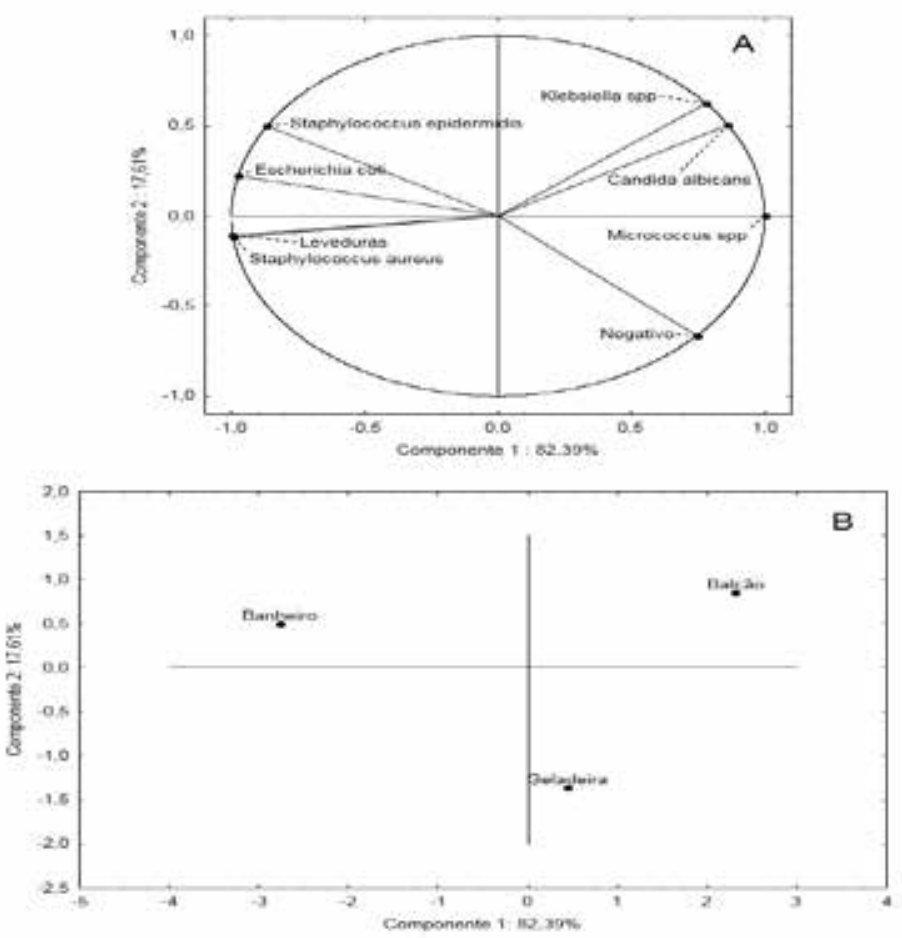

Fonte: As autoras

Figura 3 - Análise de Componentes Principais evidenciando a relação entre os microrganismos e os locais avaliados no estudo
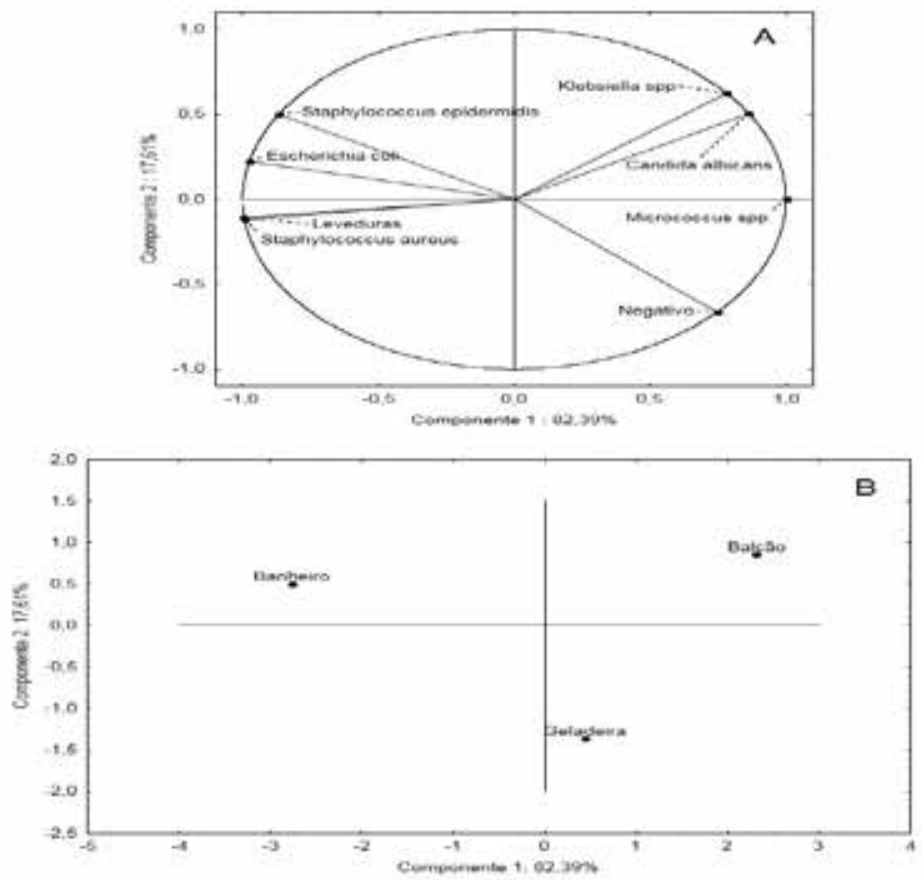

Fonte: As autoras. 


\section{Antibiograma}

O antibiograma teve por objetivo observar a resistência ou sensibilidade bacteriana a determinados antibióticos. A escolha dos antibióticos seguiu os padrões de rotina do laboratório de microbiologia. Os resultados evidenciaram os percentuais de microrganismos resistentes aos antibióticos estudados de acordo com o local de coleta (Tabela 3).

Os resultados indicam a presença de sete casos de diferenças significativas nas proporções de resistência e sensibilidade de Microcccus spp. Tais diferenças foram observadas nos seguintes antibióticos: Cefalexina (CFL), Vancomicina (VAN), Ceftazidime (CAZ), Clorafenicol (CLO), Gentamicina (GEN), Tetraciclina (TET) e Amicacina (AMI). Destes, somente o CAZ apresentou menor eficácia antimicrobiana em relação a Micrococcus spp. Para os demais antibióticos mencionados - CFL, VAN, CLO, GEN, TET e AMI - o percentual de sensibilidade de Micrococcus spp foi significativamente superior em relação ao percentual de resistência. Para os demais antibióticos avaliados, os percentuais de resistência e sensibilidade não diferiram de forma significativa $(p>0,05)$.

Tabela 3 - Resultados do antibiograma do Micrococcus spp de acordo com os diferentes antibióticos testados

\begin{tabular}{lccccc}
\hline & \multicolumn{4}{c}{ Micrococcus spp } & \\
\cline { 2 - 4 } Antibióticos & \multicolumn{2}{c}{ Resistente } & \multicolumn{2}{c}{ Sensível } & \multirow{2}{*}{ Valor $p$} \\
\cline { 2 - 4 } & $N$ & $\%$ & $N$ & $\%$ & \\
\hline OXA & 12 & 75,00 & 4 & 25,00 & 0,077 \\
CFL & 3 & 18,75 & 13 & 81,25 & 0,021 \\
ERI & 8 & 50,00 & 8 & 50,00 & 1,000 \\
CLI & 9 & 56,25 & 7 & 43,75 & 0,804 \\
VAN & 1 & 6,25 & 15 & 93,75 & 0,001 \\
PEN & 5 & 31,25 & 11 & 68,75 & 0,210 \\
AMP & 5 & 31,25 & 11 & 68,75 & 0,210 \\
CAZ & 13 & 81,25 & 3 & 18,75 & 0,021 \\
CLO & 1 & 6,25 & 15 & 93,75 & 0,001 \\
SUT & 7 & 43,75 & 9 & 56,25 & 0,804 \\
GEN & 1 & 6,25 & 15 & 93,75 & 0,001 \\
CIP & 6 & 37,50 & 10 & 62,50 & 0,454 \\
TET & 3 & 18,75 & 13 & 81,25 & 0,021 \\
TOB & 10 & 62,50 & 6 & 37,50 & 0,454 \\
AMI & 0 & 0,00 & 16 & 100 & $<0,001$ \\
\hline N & 5 & & & & \\
\hline
\end{tabular}

$\mathrm{N}$ : número de repetições referentes às análises realizadas. 
Tabela 4 - Resultados do antibiograma de Staphylococcus aureus de acordo com os diferentes antibióticos testados

\begin{tabular}{|c|c|c|c|c|c|}
\hline \multirow{3}{*}{ Antibióticos } & \multicolumn{4}{|c|}{ Staphylococcus aureus } & \multirow{3}{*}{ Valor $\mathrm{p}$} \\
\hline & \multicolumn{2}{|c|}{ Resistente } & \multicolumn{2}{|c|}{ Sensível } & \\
\hline & N & $\%$ & N & $\%$ & \\
\hline OXA & 2 & 40,00 & 3 & 60,00 & 1,000 \\
\hline CFL & 0 & 0,00 & 5 & 100 & 0,063 \\
\hline ERI & 2 & 40,00 & 3 & 60,00 & 1,000 \\
\hline $\mathrm{CLI}$ & 2 & 40,00 & 3 & 60,00 & 1,000 \\
\hline VAN & 0 & 0,00 & 5 & 100 & 0,063 \\
\hline PEN & 2 & 40,00 & 3 & 60,00 & 1,000 \\
\hline AMP & 2 & 40,00 & 3 & 60,00 & 1,000 \\
\hline CAZ & 2 & 40,00 & 3 & 60,00 & 1,000 \\
\hline CLO & 0 & 0,00 & 5 & 100 & 0,063 \\
\hline SUT & 0 & 0,00 & 5 & 100 & 0,063 \\
\hline GEN & 0 & 0,00 & 5 & 100 & 0,063 \\
\hline $\mathrm{ClP}$ & 0 & 0,00 & 5 & 100 & 0,063 \\
\hline TET & 0 & 0,00 & 5 & 100 & 0,063 \\
\hline TOB & 2 & 40,00 & 3 & 60,00 & 1,000 \\
\hline AMI & 0 & 0,00 & 5 & 100 & 0,063 \\
\hline
\end{tabular}

Os resultados da Tabela 4 evidenciam que não existem diferenças estatisticamente significativas na comparação das proporções de sensibilidade e resistência de Staphylococcus aureus no que se refere aos antibióticos estudados. Os percentuais de sensibilidade foram superiores aos de resistência, apesar da ausência de diferenças significativas nas proporções. De certo modo, tais diferenças não foram significativas, mesmo apresentando $100 \%$ de sensibilidade, devido à falta de representatividade amostral, ou seja, somente cinco casos de contaminação por Staphylococcus aureus foram testados pelo antibiograma.

O mesmo fato ocorreu com a contaminação por Escherichia coli (Tabela 5), que apresentou somente um caso, impossibilitando a realização de uma proporção.

De acordo com os resultados da Tabela 5, verificou-se que Escherichia coli apresentou o padrão de sensibilidade aos antibióticos CAZ, GEN, Ciprofloxacina (CIP), Tobramicina (TOB) e AMI. Para os demais antibióticos estudados, o referido microrganismo exibiu elevada resistência para todas as cepas isoladas. 
Tabela 5 - Resultados do antibiograma da Escherichia coli de acordo com os diferentes antibióticos testados. Fernandópolis, SP, 2019

\begin{tabular}{|c|c|c|c|c|}
\hline \multirow{3}{*}{ Antibióticos } & \multicolumn{4}{|c|}{ Escherichia coli } \\
\hline & \multicolumn{2}{|c|}{ Resistente } & \multicolumn{2}{|r|}{ Sensível } \\
\hline & $\mathrm{N}$ & $\%$ & N & $\%$ \\
\hline OXA & 1 & 100 & 0 & 0,00 \\
\hline CFL & 1 & 100 & 0 & 0,00 \\
\hline ERI & 1 & 100 & 0 & 0,00 \\
\hline $\mathrm{CLI}$ & 1 & 100 & 0 & 0,00 \\
\hline VAN & 1 & 100 & 0 & 0,00 \\
\hline PEN & 1 & 100 & 0 & 0,00 \\
\hline AMP & 1 & 100 & 0 & 0,00 \\
\hline CAZ & 0 & 0,00 & 1 & 100 \\
\hline CLO & 1 & 100 & 0 & 0,00 \\
\hline SUT & 1 & 100 & 0 & 0,00 \\
\hline GEN & 0 & 0,00 & 1 & 100 \\
\hline CIP & 0 & 0,00 & 1 & 100 \\
\hline TET & 1 & 100 & 0 & 0,00 \\
\hline TOB & 0 & 0,00 & 1 & 100 \\
\hline AMI & 0 & 0,00 & 1 & 100 \\
\hline
\end{tabular}

Fonte: As autoras.

Em relação a Staphylococcus epidermidis e Klebsiella spp verificou-se que as cepas isoladas apresentaram sensibilidade a todos os antibióticos avaliados.

\section{DISCUSSÃO}

A contaminação microbiana do ar em ambientes hospitalares é afetada por biopartículas transportadas pelo ar, sendo avaliada a existência, quantidade e tipos de microrganismos. Existem amplas variedades de fatores que influenciam as contagens de bactérias e fungos no ar e, portanto, influenciam as taxas de infecções relacionadas à assistência à saúde (LIM; KIM; CHO, 2010; GODINI et al., 2015; LAX; GILBERT, 2015; SIVAGNANASUNDARA et al., 2019).

O nível e a diversidade da biocontaminação nos ambientes hospitalares dependem de diferentes fatores, como o número e as atividades dos visitantes, sistema de ventilação, pacientes e suas atividades que contribuem para a disseminação de bioaerossóis, o layout de salas de hospitais, processos e métodos de desinfecção, ar e poeira ao ar livre e outros fatores (NASIR et al., 2015; GHANIZADEH; GODINI, 2018; TOLABI; ALIMOHAMMADI; HASSANVAND, 2019). 
Os bioaerossóis são partículas transportadas pelo ar, constituídos por bactérias, vírus, fungos e parasitas, que invadem o corpo humano por via aérea, via oral e transcutânea (MIRHOSEINI et al., 2015; BIELAWSKA-DRÓZD et al., 2018; SIVAGNANASUNDARA et al., 2019). As partículas transportadas pelo ar têm alto significado em diferentes partes dos hospitais. Os bioaerossóis podem se originar de pacientes ou várias características hospitalares internas, tais como numero de leitos por sala, tipos de doenças, processos de desinfecção, entre outros, e fontes ambientais externas. Comparados aos ambientes externos, os espaços internos podem potencialmente colocar os seres humanos em maior risco, porque estes locais apresentam menor ventilação, favorecendo o aumento de bioaerossóis (GODI$\mathrm{NI}$ et al., 2015; RIBEIRO et al., 2019). Este achado destaca a necessidade de estudar a qualidade microbiológica do ar dos locais de trabalho (HERA et al., 2018).

Estudos realizados por Hera et al. (2018), na parte interna e externa de um aterro sanitário nas Filipinas, evidenciaram que a composição bacteriana dos bioerossóis foi maior de cocos Gram-positivos que de bacilos Gram-positivos e de bactérias Gram-negativas. Estes autores isolaram Staphylococcus aureus e Bacillus spp. Segundo Lax e Gilbert (2015), Teerawattanapong, Panichi e Kulpokin (2018), Walter, Haller e Quinten (2018), os patógenos mais comuns causadores das Iras são Clostridium difficile, Enterococcus spp, Staphylococcus aureus, Klebsiella spp, Acinetobacter spp, Pseudomonas aeruginosa e Escherichia coli.

Segundo Agaba et al. (2017) e Teerawattanapong, Panichi e Kulpokin, (2018), bactérias isoladas em bioerossóis apresentam resistência a antimicrobianos, o que representa uma séria ameaça à saúde humana e é um grande desafio para a medicina moderna (JANKOWIAK et al, 2020). Na presente pesquisa verificou-se que as cepas de Micrococcus spp e de E. coli isoladas na UTI apresentaram padrão de resistência elevado, enquanto que o perfil de resistência de S. aureus foi baixo e Klebsiella spp e $S$, epidermidis foram sensíveis a todos os antibióticos avaliados. Os resultados obtidos evidenciaram que os bioaerossóis na UTI possuíam microrganismos potencialmente patogênicos, e algumas cepas apresentaram perfil de resistência elevada a antibióticos.

A exposição a essas partículas presentes no ar pode resultar em distúrbios respiratórios e outros efeitos adversos à saúde, como infecções, pneumonite por hipersensibilidade e reações tóxicas. Além disso, o contato a longo prazo de pessoas com bioaerossóis contaminados pode influenciar nos distúrbios mentais e na capacidade de aprendizagem de uma pessoa (NARUKA; GAUR, 2014). Diferentes condições ambientais, como temperatura, luz ultravioleta e umidade desempenham um papel no controle do crescimento de partículas em suspensão, no entanto os microrganismos conseguem alcançar novos hospedeiros para sua sobrevivência (SHEIK; RHEAM; SHEHRI, 2015).

De acordo com Godini et al. (2015), Hera et al. (2018) e Sivagnanasundara et al. (2019), os hospitais devem executar protocolos mais drásticos e medidas de controle de infecções. O monitoramento regular da aerobiota hospitalar é, particularmente, recomendado. Altas concentrações microbianas em vários ambientes internos apontam um risco potencial à saúde, predispondo à ocorrência de doenças respiratórias. Como as bactérias e fungos isolados podem ser patogênicos, é pertinente que sua presença seja controlada. Esforços devem ser feitos para minimizar a transmissão aérea de microrganismos oportunistas e seu potencial impacto nos pacientes (LAX; GILBERT, 2015; AGABA et al., 2017, HERA et al., 2018).

Editora Unijuí - Revista Contexto \& Saúde - ISSN 2176-7114 - v. 21, n. 43, jul./set. 2021 


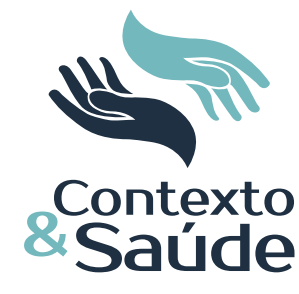

\section{CONCLUSÃO}

De acordo com a metodologia utilizada e mediante os resultados obtidos pode-se concluir que:

Os bioerossóis da UTI avaliada apresentam microrganismos viáveis potencialmente patogênicos. As espécies isoladas pertenciam às espécies: Staphylococcus aureus, S. epidermidis, Microccus spp, Escherichia coli, Klebsiella spp, Candida albicans e Candida spp.

As espécies Microccus spp e E. coli apresentaram perfil elevado de resistência a antimicrobianos, enquanto que $S$. aureus, Klebsiella spp e $S$. epidermidis evidenciaram alto padrão de sensibilidade.

Estas divergências de ocorrência de microrganismos nos diferentes locais avaliados pode direcionar o processo de limpeza e desinfecção destes locais, mostrando que em áreas específicas há predominância de determinados tipos de microrganismos potencialmente patogênicos e direcionar um planejamento para evitar a proliferação destes patógenos, minimizando a probabilidade de infecções na UTI, garantindo a segurança dos pacientes ali internados.

É evidente que pesquisas permanentes do ambiente hospitalar para avaliar a presença e composição dos bioaerossóis são necessárias, considerando que os visitantes, e principalmente os pacientes, emitem microrganismos ao tossir ou espirrar. Seria particularmente importante que as unidades de saúde adotassem estas estratégias rotineiramente, para desta forma contribuir na redução da incidência de infecções hospitalares.

\section{REFERÊNCIAS}

AGABA, P. et al. Nosocomial bacterial infections and their antimicrobial susceptibility patterns among patients in Ugandan intensive care units: a cross sectional study. BMC Res Notes, v. 10, p. 349-360, 2017. DOI: https://doi.org/10.1186/s13104-017-2695-5

BIELAWSKA-DRÓZD, A. et al. Microbiological analysis of bioaerosols collected from Hospital Emergency Departments and ambulances. Ann Agric. Environ. Med., v. 25, n. 2, p. 274-279, 2018. DOI: https://doi.org/10.26444/aaem/80711

BRASIL. Ministério da Saúde. Resolução RDC no 50, de 21 de fevereiro de 2002. Brasília, DF: Ministério da Saúde/Anvisa, 2002. Disponível em: http://portal.anvisa.gov.br/documents/33880/2568070/res0050_21_02_2002.pdf/ca7535b3-818b-4e9d-9074-37c830fd9284.

CALFEE, D. P. Crisis in hospital-acquired, healthcare-associated infections. Annual Review of Medicine, v. 6, p. 359-371, 2011.

CLSI. Clinical \& Laboratory Standards Institute. Verification of Commercial Microbial Identification and Antimicrobial Susceptibily Testing Systems. 1. ed. CLSI guideline M52. Wayne, PA: Clinical and Laboratory Institute, 2015.

CLSI. Clinical \& Laboratory Standards Institute. Suggested Grouping of US-FDA Approved Antimicrobial Agents That Should Be Considered for Routine Testing and Reporting on Nonfastidious Organisms by Clinical Laboratories. 29. ed. CLSI guideline M100-S29. Wayne, PA: Clinical and Laboratory Institute, 2019.

FLETCHER, L. A. et al. The importance of bioaerosols in hospital infections and the potential for control using germicidal ultraviolet irradiation. In: MONEDERO, M. A. S.; GARCIA-FERRANDEZ, A. R. (ed.). Proceedings of the 1st Seminar on Applied Aerobiology, Murcia, Spain, 20th May 2004. 1st Seminar on Applied Aerobiology, 20 May 2004. Murcia, Spain: Centro de Edafología y Biología Aplicada del Segura, Spain, 2004.

GHANIZADEH, F.; GODINI, H. A review of the chemical and biological pollutants in indoor air in hospitals and assessing their effects on the health of patients, staff and visitors. Rev. Environ. Health, v. 33, p. 231-245, 2018.

Editora Unijuí - Revista Contexto \& Saúde - ISSN 2176-7114 - v. 21, n. 43, jul./set. 2021 
GODINI, H. et al. Bio-aerosols concentrations in different wards of Khorramabad Hospital, Iran, 2013. Int. J. Env. Health Eng., v. 4, p. 23-28, 2015.

HAYLEEYESUS, S. F.; MANAYE, A. M. Microbiological quality of indoor air in university libraries. Asian Pacific J. Trop. Biomed., v. 4, (Suppl 1), p. S312-S317, 2014.

HERA, A. et al. Vital Detection of pathogenic bioaerosols and occupational risk in a Philippine landfill site. Arch. Environ. Occup. Health, v. 73, n. 2, 2018.

JANKOWIAK, E. et al. Microbiological air quality in pharmacies and an antibiotic resistance profile of staphylococci species. Aerobiol., v. 36, p. 551-563, 2020. DOI: https://doi. org/10.1007/s10453-020-09651-x.

KALWASIŃSKA, A.; BURKOWSKA, A.; WILK, I. Microbial air contamination in indoor environment of a university library. Ann Agric Environ Med, Lublin, v. 19, n. 1, p. 25-29, 2012. LAX, S.; GILBERT, J. A. Hospital-associated microbiota and implications for nosocomial infections. Trends Mol. Med., v. 21, p. 427-432, 2015. DOI: https://doi.org/10.1016/j. molmed.2015.03.005.

LIM, T.; KIM, B. S.; CHO, J. The predictions of infection risk of indoor airborne transmission of diseases in high-rise hospitals: tracer gas simulation. Energ Buildings, v. 42, p. 1172-1181, 2010.

MAGILL, S. S. et al. Multistate point-prevalence survey of health care - associated infections. N. Engl. J. Med., v. 3.701, p. 198-208, 2014. DOI: https://doi.org/10.1056/NEJMoa1306801

MIRHOSEINI, S. H. et al. Monitoring of airborne bacteria and aerosols in different wards of hospitals - Particle counting usefulness in investigation of airborne bacteria. Ann. Agricult. Environ. Med., v. 22, n. 4, p. 670-973, 2015.

MURAKAMI, B. M.; SANTOS, E. R. Enfermagem em terapia intensiva. Barueri, SP: Manole, 2015.

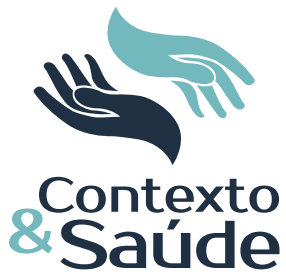

NARUKA, K.; GAUR, J. Distribution Pattern of Airborne Bacteria and Fungi at Market Area. American-Eurasian J. Sci. Res., v. 9, n. 6, p. 186-192, 2014.

NASIR, Z. A. et al. Evaluation of total concentration and size distribution of bacterial and fungal aerosol in healthcare built environments. Indoor and Built Environment, v. 24, n. 2, p. 269-279, 2015.

RIBEIRO, L. F. et al. Microbial Community Profiling in Intensive Care Units Expose Limitations in Current Sanitary Standards. Front. Public Health, v. 7, p. 240-247, 2019. DOI: https://doi.org/10.3389/fpubh.2019.00240

SETLHARE, G. et al. Identification of airborne microbiota in selected areas in a healthcare setting in South Africa. BMC Microbiol., v. 14, n. 100, p. 1-10, 2014. DOI: http:// www.biomedcentral.com/1471-2180/14/100

SHEIK, G. B.; RHEAM, A. I. A. A.; AL SHEHRI, Z. S. Assessment of Bacteria and Fungi in air from College of Applied Medical Sciences (Male) at AD-Dawadmi, Saudi Arabia. Int Res J. Biol. Sci., v. 4, n. 9, p. 1-5, 2015.

SILVEIRA, D. T.; CÓRDOVA, F. P. A pesquisa científica. In: GERHARDT, Tatiana Engel; SILVEIRA, Denise Tolfo (org.). Métodos de pesquisa. Porto Alegre: Ed. UFRGS, 2009. p. 31-42.

SIVAGNANASUNDARA, M. P. et al. Assessment of airborne bacterial and fungal communities in selected areas of teaching Hospital, Kandy, Sri Lanka. BioMed Res. Int., v. 2019, p. 11- 22, 2019. DOI: https://doi.org/10.1155/2019/7393926

TEERAWATTANAPONG, N.; PANICH, P.; KULPOKIN, D. A systematic review of the burden of multidrug resistant healthcare-associated infections among intensive care unit patients in Southeast Asia: the rise of multidrug-resistant Acinetobacter baumannii. Infect Control Hosp Epidemiol., v. 39, p. 525-533. 2018. DOI: https://doi.org/10.1017/ice.2018.58

TOLABI, Z.; ALIMOHAMMADI, M.; HASSANVAND, M. S. The investigation of type and concentration of bio-aerosols in the air of surgical rooms: A case study in Shariati hospital, Karaj. MethodsX, v. 6, p. 641-650, 2019. DOI: https://doi.org/10.1016/j.mex.2019.03.016 WALTER, J.; HALLER, S.; QUINTEN, C. Healthcare-associated pneumonia in acute care hospitals in European union/European economic area countries: an analysis of data from a point prevalence survey, 2011 to 2012. Eurosurveillance, v. 23, p. 1-12, 2018. DOI: https://doi.org/10.2807/1560-7917.ES.2018.23.32.1700843

WINN-JUNIOR, W. C.; ALLEN, S. D.; JANDA, W. M. Koneman. Diagnóstico microbiológico: texto e atlas colorido. 6. ed. Rio de Janeiro: Guanabara-Koogan, 2012.

ZAR, J. H. Biostatistical Analysis. 5. ed. Essex: Prentice Hall, 2009. 